\title{
العلاقات الايرانية - الامريكية بعد الاتفاق النووي
}

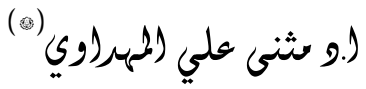

الملخص

ان نقطة التحول الاساسية في السياسة الامريكية تجاه ايران نجاح الثورة الاسلامية في

ايران I 9V9 ، اذ منذ ذلك الوقت تأزمت العلاقات بين البلدين ـ وبعد احداث 11

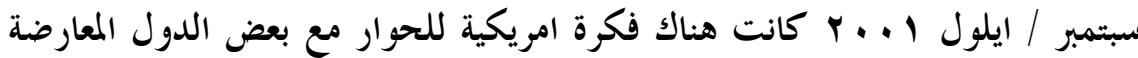
للسياسة الامريكية ومنها ايران ـ وفي عام ع . .. طرحت الولايات المتحدة ( مشروع الشرق الاوسط الكبير)، والذي احتوى على مجموعة مقترحات سياسية واقتصادية وثقافية للمنطقة ، تصب بمجملها في مصلحة الولايات المتحدة و( اسرائيل ) ، وهو ما

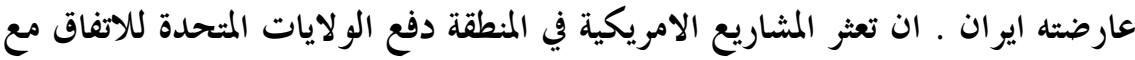

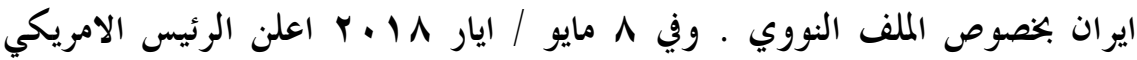
دونالد ترامب رسميا خروج الولايات المتحدة من الاتفاق النووي مع ايران و بعدها في ه نوفمبر / تشرين الثاني فرضت الولايات المتحدة مجموعة عقوبات على ايران ، الا ان الانسحاب الامريكي من الاتفاق وفرض العقوبات رفضته اغلب دول العالم مما يعني ان

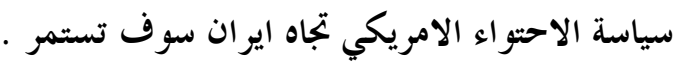

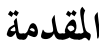

ان نقطة التحول الاساسية في السياسة الامريكية تجاه ايران كانت نجاح الثورة

الاسلامية في ايران 9V9 9 ، و واختلال التوازن الاستراتيجي في المنطقة ، ذلك التوازن الذي كانت ترعاه الولايات المتحدة منذ بداية السبعينيات في القرن الماضي ، والذي كان يرتكز على التفوق العسكري الايراني بعده صمام الامان لحماية المصالح الامريكية في الخليج. اذ بسقوط الشاه خسر الامريكيون حليفا قويا ، ولكنهم لم يخسرو كل 
النفوذ الذي يتمتعون به في المنطقة. وبدات تتبلور تدريجيا الصورة الجديدة للسياسة

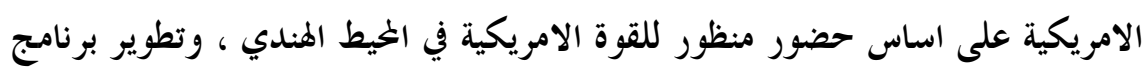

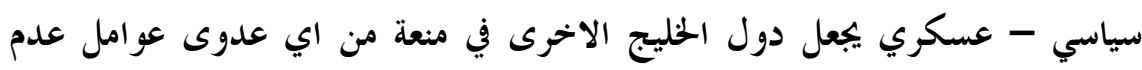

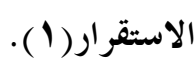

اولا: السياسة الامريكية تجاه ايران خحلال حرب الخليج الاولى والثانية

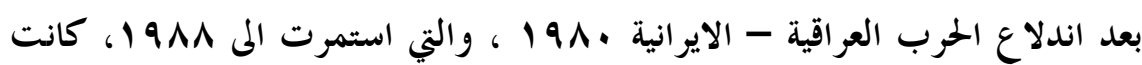

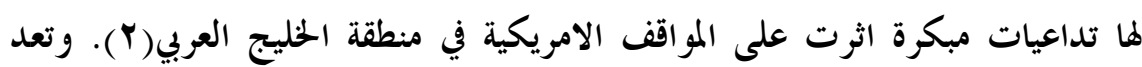

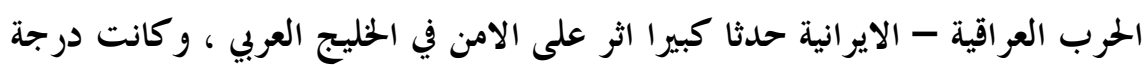

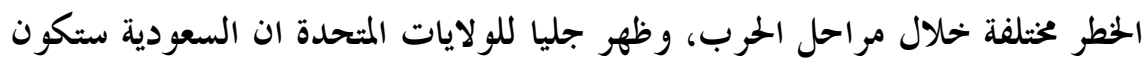

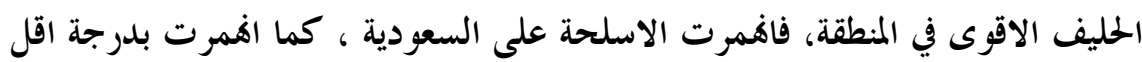
على بقية دول الخليج، و كانت هناك آثار في وضع دول الخليج في لعبة الامن في المنطقة

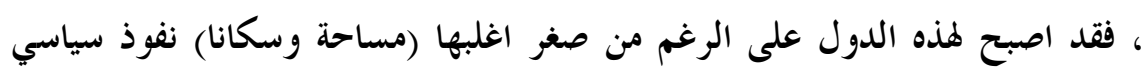

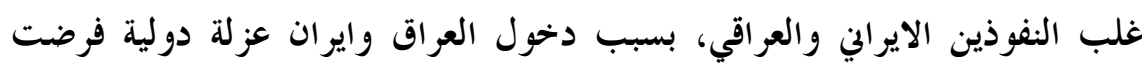

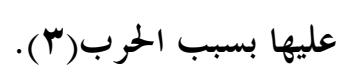

وبعد حرب الخليج الثانية 199 19 اختلفت السياسة الامريكية تجاه منطقة الخليج

العربي فقد اصبحت تستند الى الر كائز الاستر اتيجية الاتية:

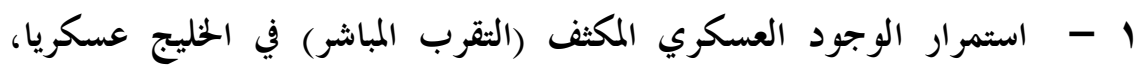

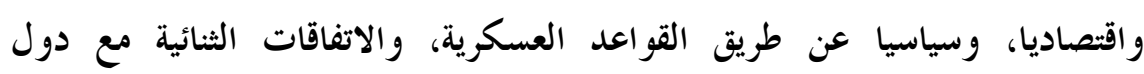

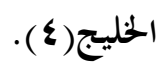
Y - حماية امن المنطقة من كل من العراق وايران، وهو ما سمي ( بسياسة الاحتواء

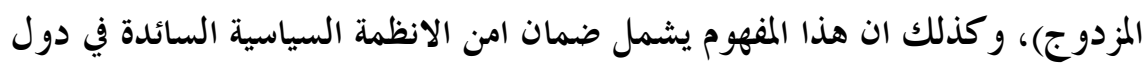

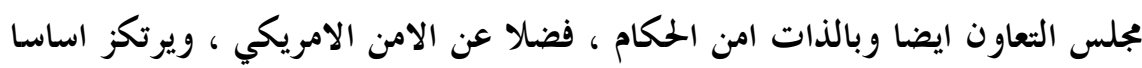

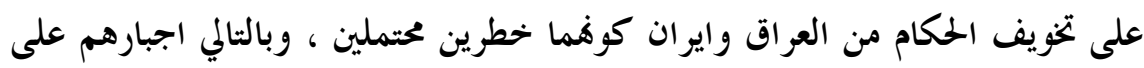


قبول الحماية الامريكية، وشراء المزيد من الاسلحة والمعدات، فضلا عن دفع مبالغ للولايات المتحدة عن هذه الحماية(ه).

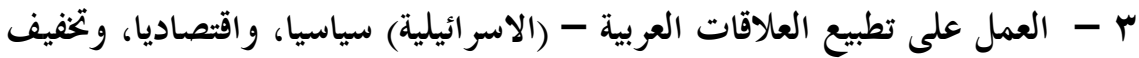
المقاطعة العربية ( لاسرائيل ) من خلال مشروع الشرق الاوسط الجديد الذي طرح

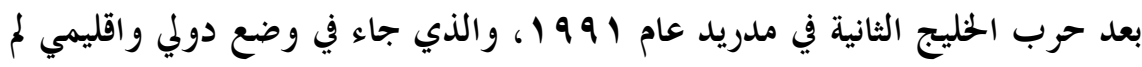

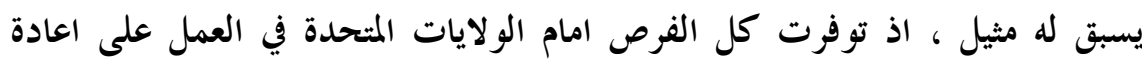

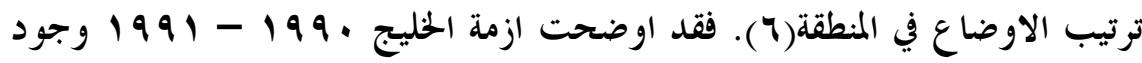

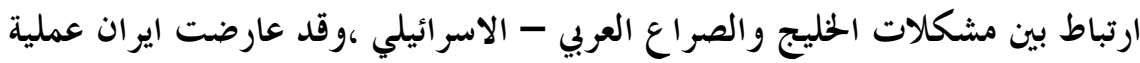

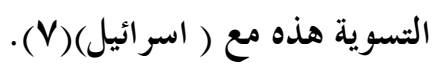

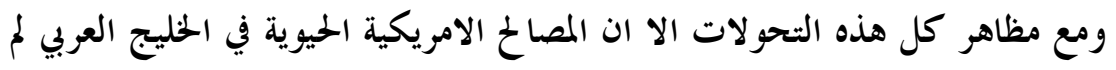

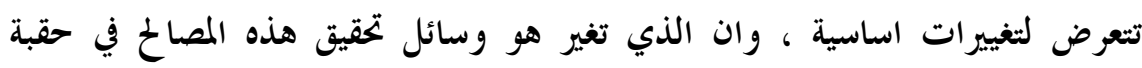
التسعينيات من القرن الماضي ( 1 ) ) .

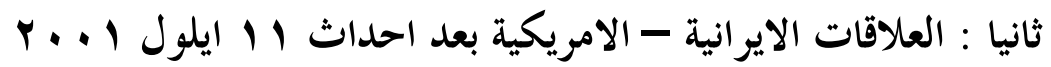
ان الازمة التي اثارتما احداث || سبتمبر / ايلول | . . ب كانت ازمة عالمية وشاملة،

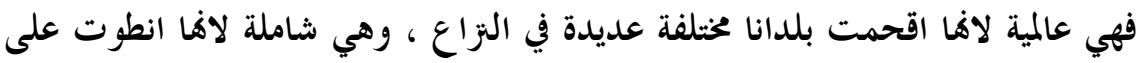
تاثير في مستويات متعددة عسكرية، وسياسية ، واقتصادية، وثقافية (9).

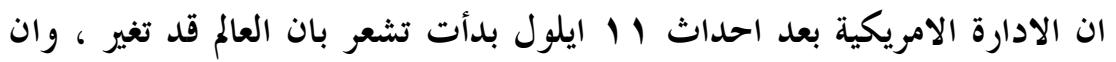

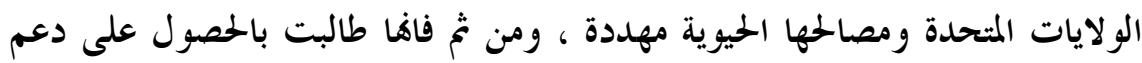
قوي من حلفائها في منطقة الخليج العربي لمواجهة مااسمته بالارهاب ضد ضد الولايات

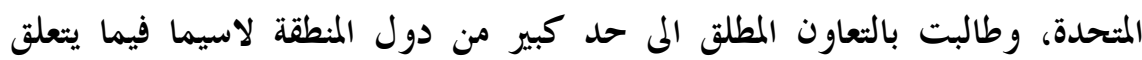
بالتعرف على هوية الاشخاص والافراد الذين قدموا الدعم او لعبوا دورا في هذه العمليات، او شاركوا فيها بطريقة او اخرى، او يقدموا الدعم لمنظمات اسلامية

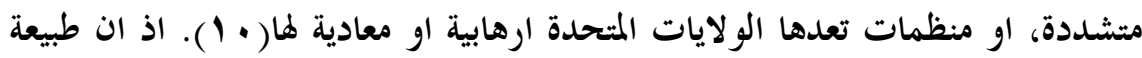
حرب الولايات المتحدة مع الارهاب بعد احداث 11 ايلول لا يمكن حصرها في منطقة 
جغر افية بعينها، مما يعني ان الولايات المتحدة تتواجد بقواتها لحماية مصالحها المنتشرة في

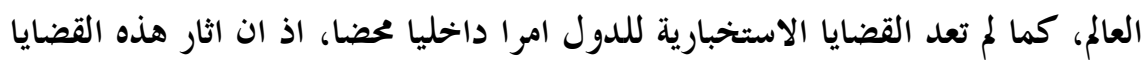

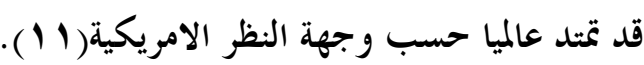

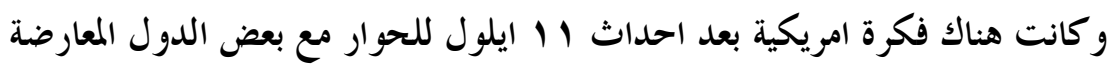

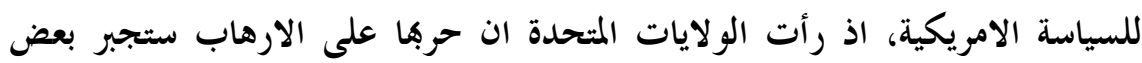
الدول على عدم اظهار اي دعم لما يعرف بــ(الارهاب) حتى وان كانت معادية ل لسياسات الولايات المتحدة.

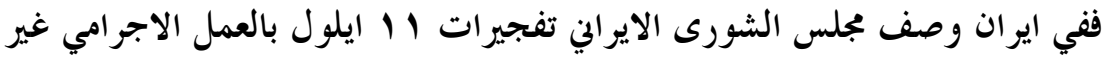
المقبول، وقام 190 اعربوا فيها عن تعاطفهم مع الشعب الامريكي وطالبوا بوصف العمل بالارهاب.

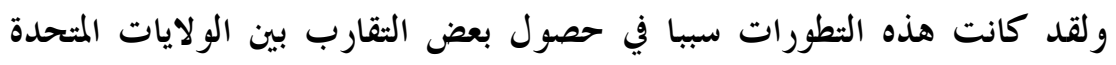

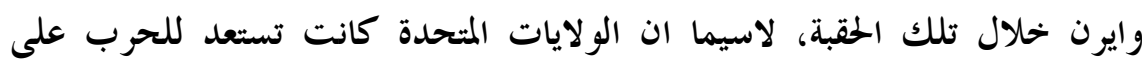

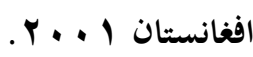
فرغم ان ايران لم ترغب بالتدخل العسكري الامريكي في افغانستان ،الا ان المصاح

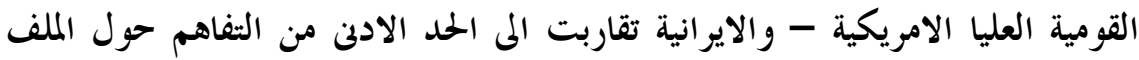

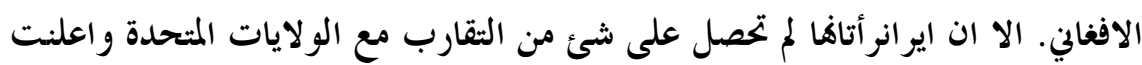

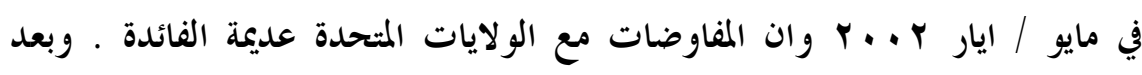
تصنيف ايران في (محور الشر) من قبل الولايات المتحدة عادت الامور بين البلدين المى الى المات

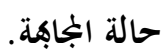
وبعد ان شعرت ايران بالتداعيات السلبية للوجود الامريكي في افغانستان، اتبعت

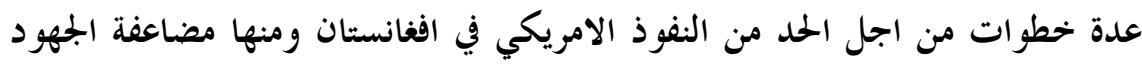
الدبلوماسية من اجل كسب ثقة القادة الاففان الجحد وتقوية حلفائها الافغان التقليدين.

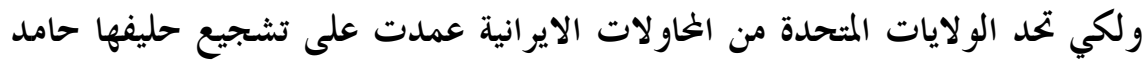

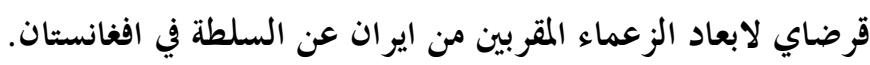




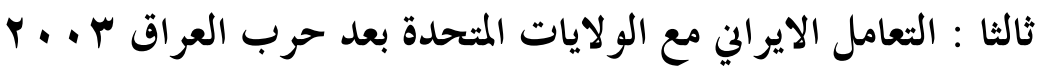

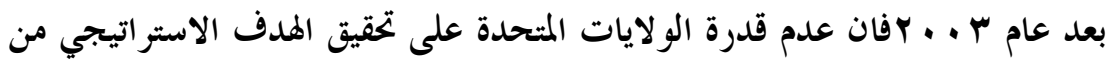

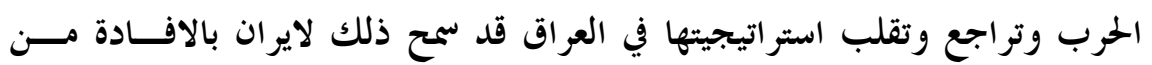

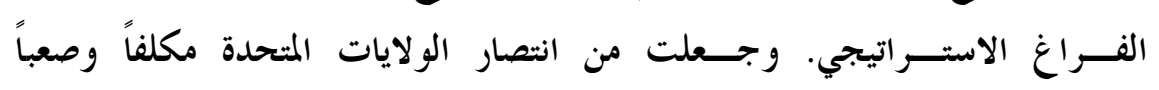

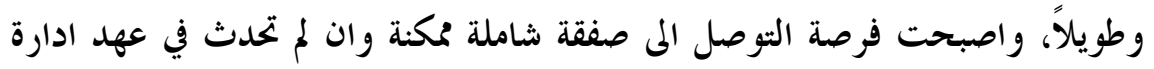

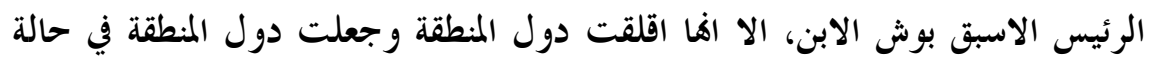

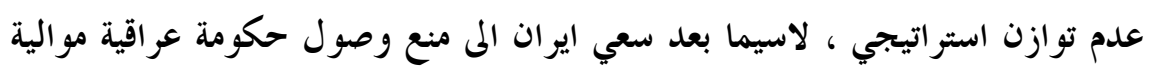

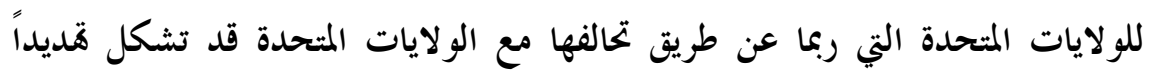

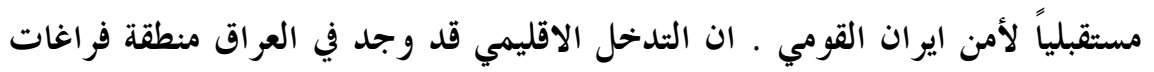

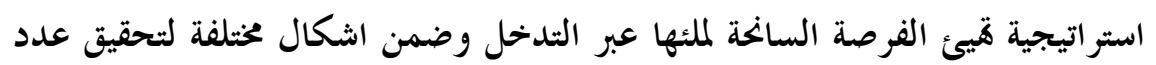

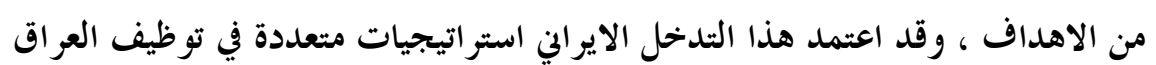

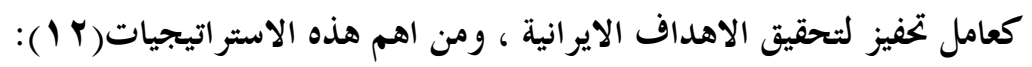

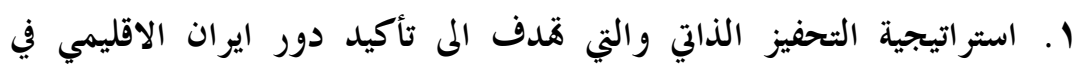

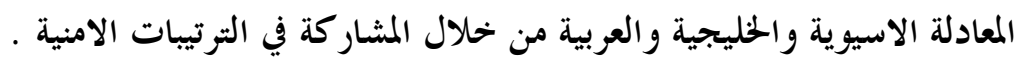

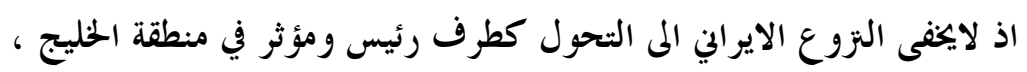

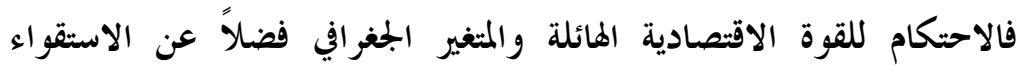
بالمقدرة النووية كل ذلك سيعزز مقدرة ايران في المنطقة وسيجعلها عضواً

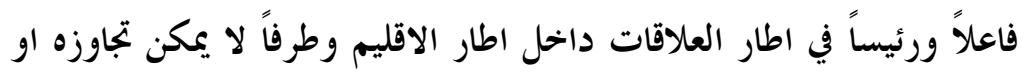

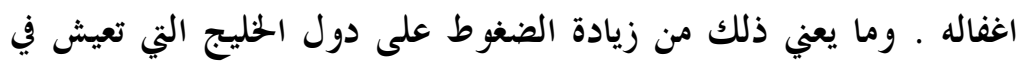
كابوس تحول ايران المى قوة نووية فمنطق القدرة الايرانية يتحدد بالاستقواء

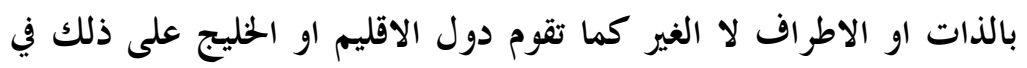

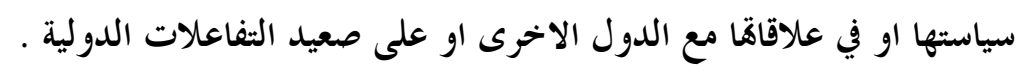


Y. استراتيجية المساومات وقدف الم تحقيق اعلى درجة من المنفعة من خلال

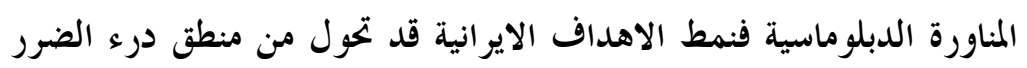

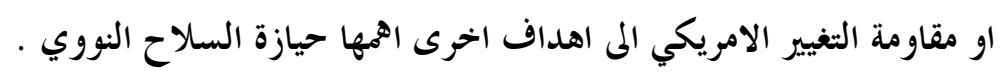

$$
\text { رابعا : اثر المتغير الروسي على العلاقات الايرانية - الامريكية }
$$

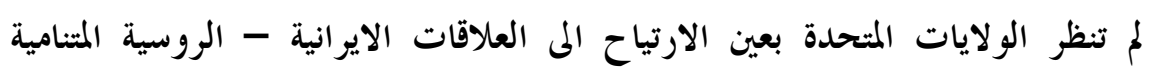

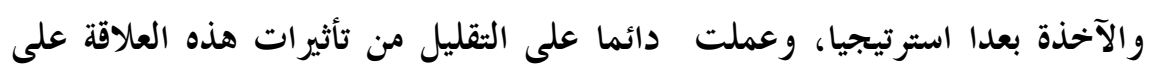

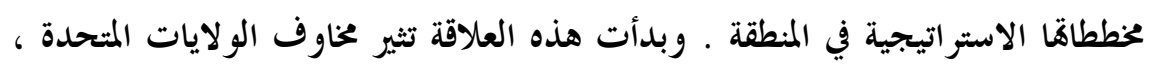
ولاسيما بعد 1990 وهو العام الذي وقعت فيه روسيا عقدا مع ايران بقيمة مليار دولار لبناء مفاعلين نوويين في ايران ، وعلى أثرها هدد زعماء الكونكرس الامريكي بقطع المساعدات عن روسيا . فمن المعروف ان روسيا هي الحليف الاول لايران فيما يتصل بالبرنامج النووي الايراني ، لكن معروف ايضا في المقابل ان هذه المواقف الروسية لاتنبع من اعتبارات

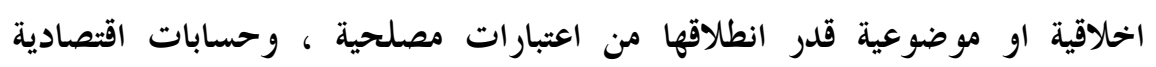

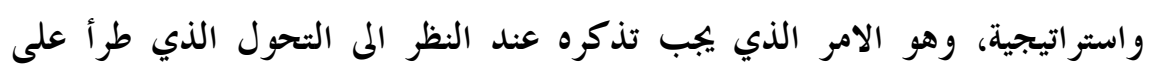

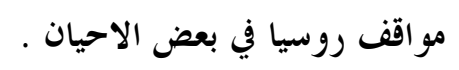

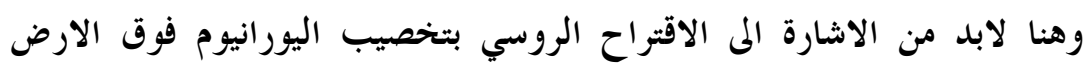

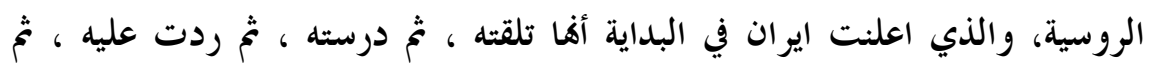

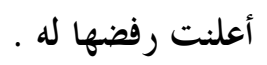

ومع ذلك فقد تصاعدت وتيرة العلاقات بين روسيا وايران ، وتحديدا في الجحال

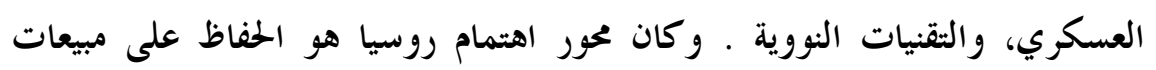

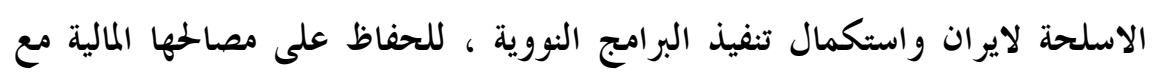
ايران . ولاستخدام هذه العلاقة مع ايران كاحدى وسائل المواجهة مع الولئل الوايات

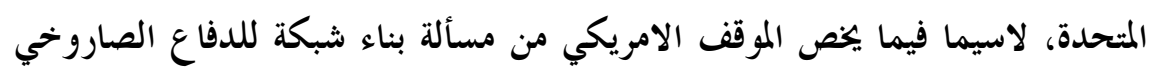
المضاد للصواريخ البالستية (ب ا) ). 


$$
\text { خامسا : الاتفاق النووي الايراني - الامريكي }
$$

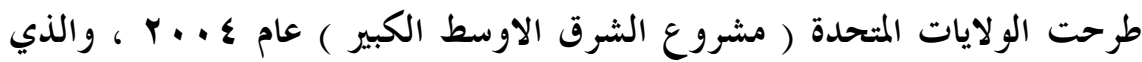
احتوى على مجموعة مقترحات سياسية واقتصادية وثقافية للمنطقة ، تصب بمجملها في تحقيق المصالح الامريكية عن طريق ( الاعتمادية المتبادلة ) بين دول المنطقة بضمنها

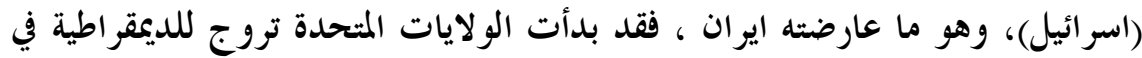
المنطقة، ليس بدافع دعم الشعوب وانما لتمهيد الارضية لتحقيق المصالح الاقتصادية

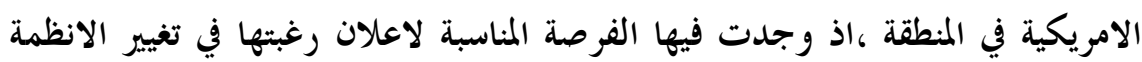

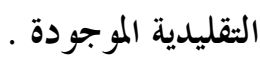

ان التداعيات الاهم للمقترحات الامريكية تتمثل بالنظرة الجديدة للامن في المنطقة ، والقائمة على جعل ثثن اي قديد لامن المنطقة وفق وجهة النظر الامريكية مكلف لهم

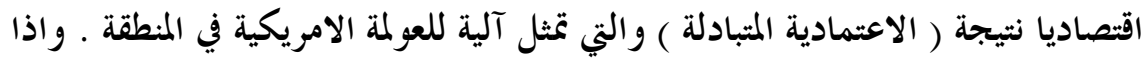
كان الهدف الامني الاول للولايات المتحدة في المنطقة حماية ( اسرائيل ) فان التهليد لهديد

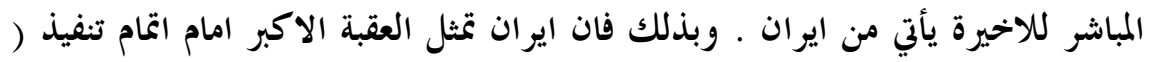
مشروع الشرق الاوسط الكبيز ) ، لاسيما في آليته الرئيسة ( الاعتمادية المتبادلة ) . ووفق هذا التحليل فان ايران تمثل تحدي لمشاريع للولايات المثحدة في المنطقة وبالمقابل فان هذه المشاريع تمثل تحدي لايران ، وما ينتج عن التغيرات في المنطقة العربية

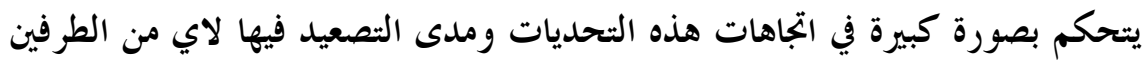
الامريكي والايراني . وهناك حقيقة مهمة لايمكن انكارها تؤثر في استثمار الطرفين

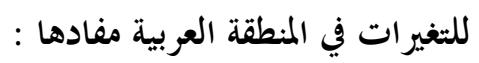

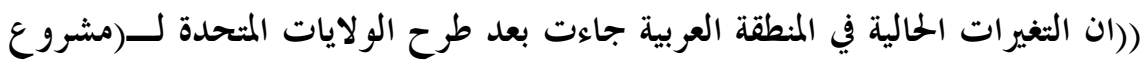
الشرق الاوسط الكبير ) ، ولكن هذا لا يلغي دور الشعوب العربية في هذه التغيرات ، ورغبتها في تحقيق اهداف قد تتعارض مع اهداف الولايات المتحدة)). وهذه الاسباب دفعت الولايات المتحدة للاتفاق مع ايران بخصوص الملف النووي ، فضلا عن اسباب اخرى تمثل مخاوف امريكية مستقبلية منها : 
1 - ان التيار الاسلامي تيار كبير داخل المد الشعبي الداعي للتغيير في المنطقة العربية ، ومن المعروف ان الثيارات الاسلامية بغض النظر عن توجهاهما قريبة من ايران ، كونها

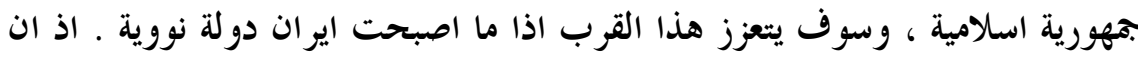
الحركات الاسلامية الممثلة للتيار الاسلامي تعد من اقوى الحركات السياسية تنظيما

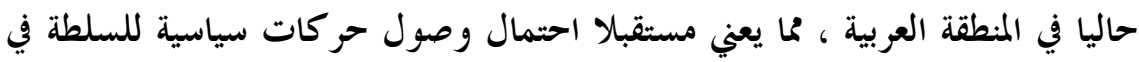

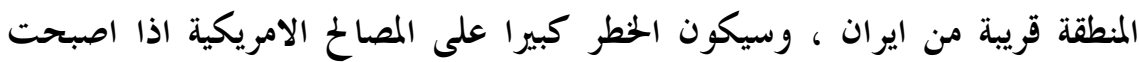

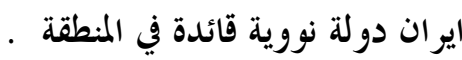
r - ان شعوب المنطقة مع اقرارها بدور الولايات المتحدة في التغيرات الحالية ، الا اها

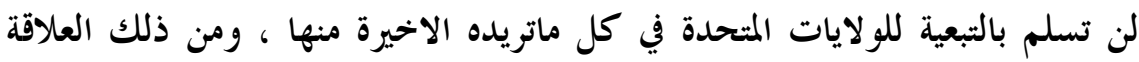

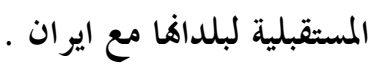
r - ان - ايران دولة اقليمية تمتلك القدرة على الثاثير في التغيرات الحالية في المنطقة العربية لحماية مصالحها ، ولكن هذه القدرة سوف تتحول قدرة اقليمية ببعد عالمي اذا

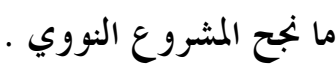

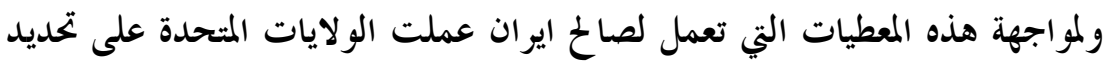

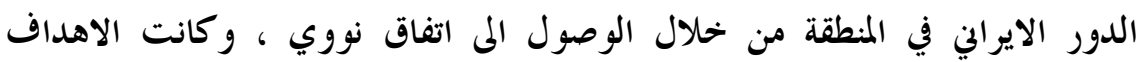
الامريكية للاتفاق النووي غير مباشرة تتمثل فيما ما يأتي:1 - العمل على اضعاف دور الحر كات الاسلامية المستقبلي في السلطة داخل البلدان العربية التي تحدث فيها التغيرات ، وبالتالي اضعاف الدور الايراني في هذه البلدان . r - ب تصعيد الضغوط على ايران فيما يخص ملفات حقوق الانسان ، من اجل استغلال هذه القضية كورقة ضغط ، لاسيما ان هذه الورقة لها ابعاد دولية .

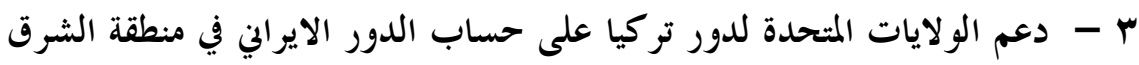
الاوسط . ع - محاولة الولايات المتحدة اشغال ايران في ملفات ممكن السيطرة عليها مع دول في

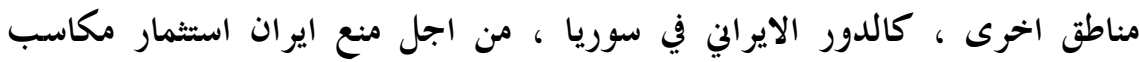

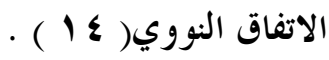


ان هذه التحديات المتبادلة بين الولايات المتحدة وايران توضح ان البلدين كانا يواجهان خيارات متناقضة نتيجة الاتفاق النووي ، مع الاقرار بحقيقة ان الثنافس بين قوة عالمية متمثلة بالولايات المتحدة وقوة اقليمية متمثلة بايران ، وهو فارق له اهميته ، فالادوات التي لدى الولايات المتحدة كقوة عالمية تمكنها من تجاوز التحديات التي تواجهها بمفردها ، لاسيما اذا هي التي روجت لهذا للاتفاق النووي ـ بينما الادوات

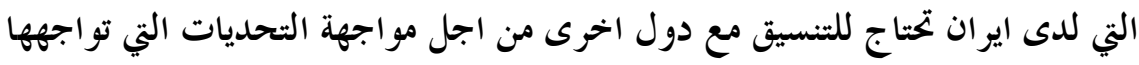

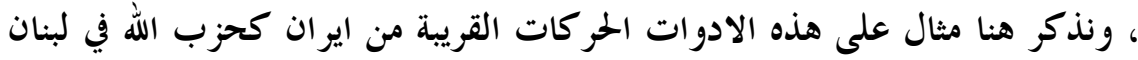

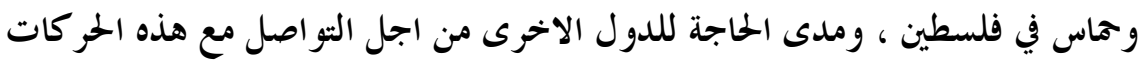

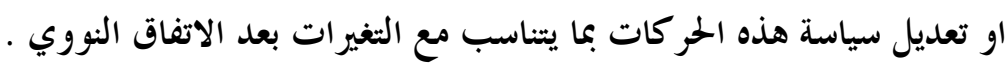
الا ان هذا لايلغي حقيقة ان ايران حققت مكاسب من الاتفاق النووي سياسية

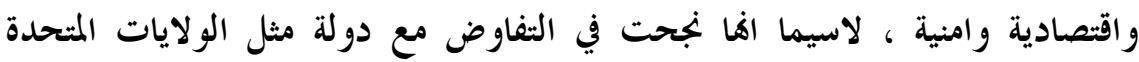
معروفة بصعوبة الثفاوض والوصول الاتفاق معها . سادسا : الانسحاب الامريكي من الاتفاق النووي

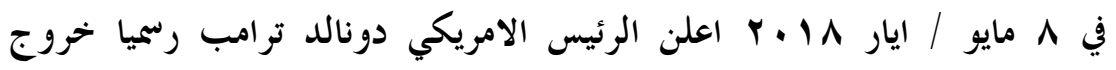

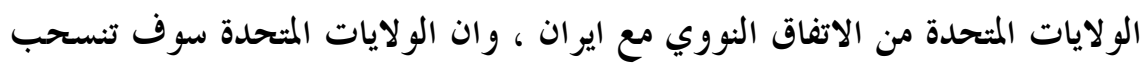

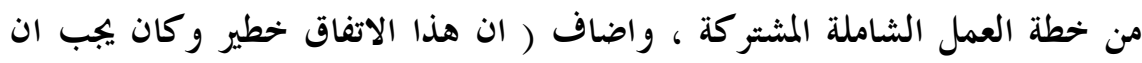
لايحدث وانه لم ولن يجلب السلام والهدوء وسنفرض اعلى مستوى من العقوبات

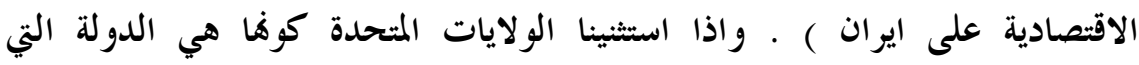
انسحبت فان كل الدول التي توصلت للاتفاق التي عرفت بمجموعة ه + 1 ( الاعضاء

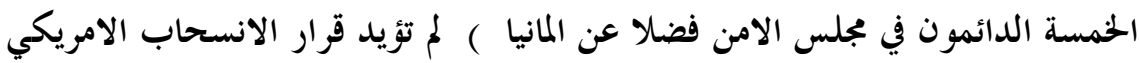

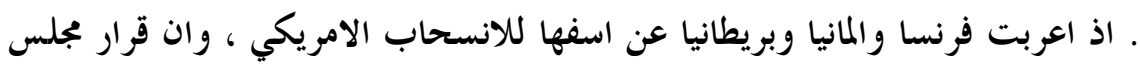

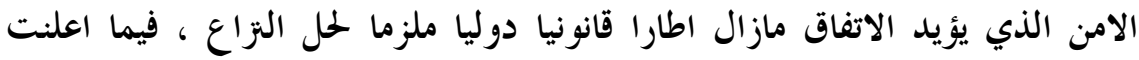

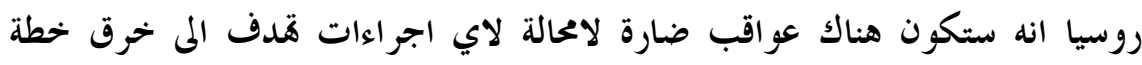

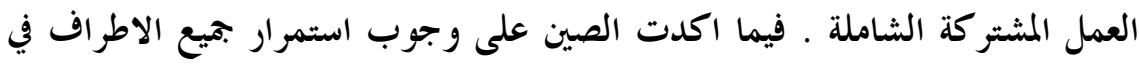


الالتزام بنهاية الاتفاق .اما الاتحاد الاوربي الذي كان من الاطراف الموقعة على خطة

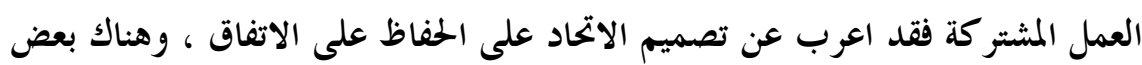

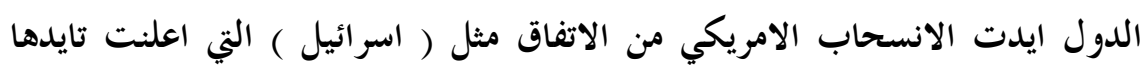

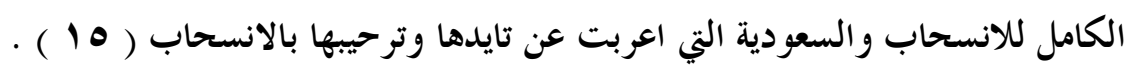

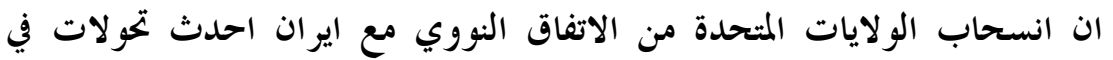

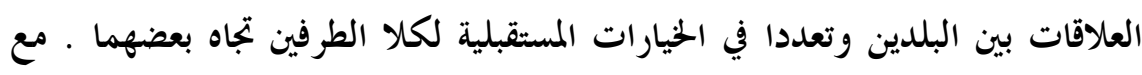
الاقرار بان هذه التحولات لاتخرج في اطارها العام عن سياسة الاحتواء التي تطبقها الولايات المتحدة تجاه ايران منذ وقت طويل ، ولا يتوقع مستقبلا اتخاذ الولايات

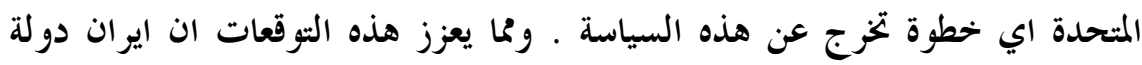

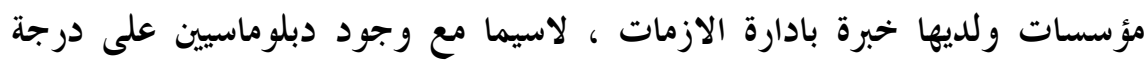
عالية من الكفاءة في ايران . كما ان الموقف الدولي الرافض للعقوبات التي فرضتها الولايات المثحدة على ايران

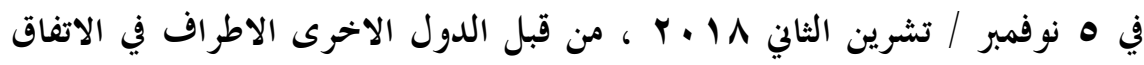

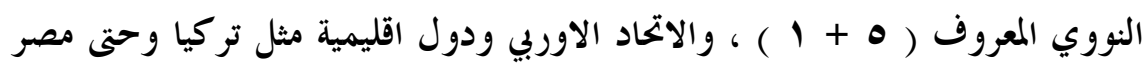

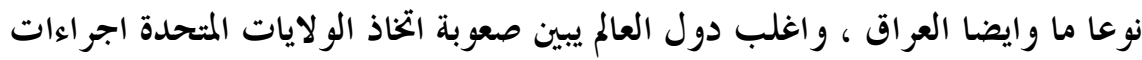
تخزج عن سياسة الاحتواء ـ فهي لم تلق تاييد في فرض العقوبات الاخيرة على ايران من

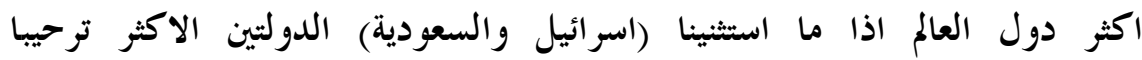
بالانسحاب ، ومن المعروف ان ( اسرائيل ) تصاعدت في الحقبة الاخيرة الانتقادات عليها حول انتهاكات حقوق الانسان في غزة بعد المسيرات السلمية الفلسطينية للعودة العرون

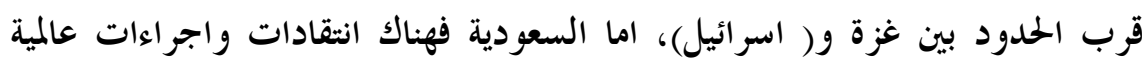
تتخذ الان ضدها على مستوى الدول والمنظمات الدولية لاسيما المعنية بحقوق الانسان بعد حادثة قتل الصحفي السعودي جمال خاشقجي داخل القنصلية السعودية في

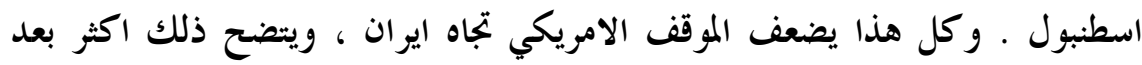

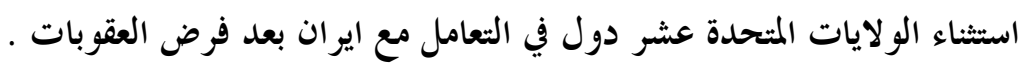




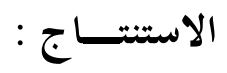

نستنتج من ذلك ان العلاقات الايرانية - الامريكية تاثرت بالتغيرات الحالية بالمنطقة

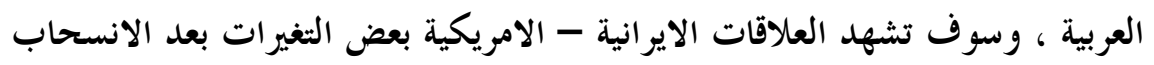

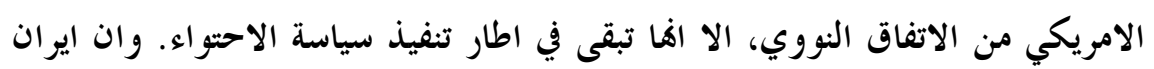

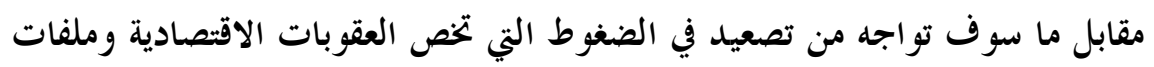

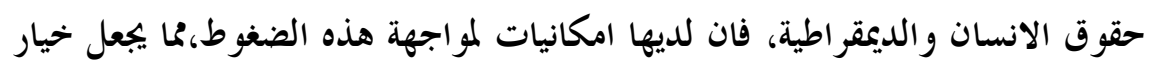
المواجهة العسكرية بين البلدين بعيد في الوقت الحاضر .

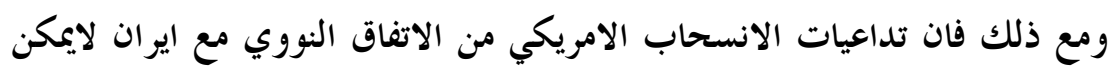

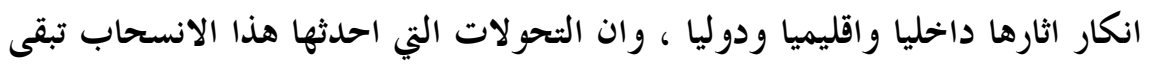
من الاهمية لما احدثثه من تداعيات سواء في الداخل الايراني ام على المستوى الحخارجي.

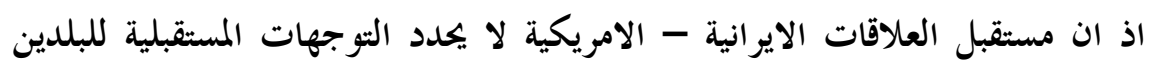
فقط، بل التوجهات المستقبلية للعديد من الدول الاقليمية، بل وحتى بعض الدول العالمية تتاثر نوعا ما توجهاتما المستقبلية بهذه العلاقات الايرانية - الامريكية.

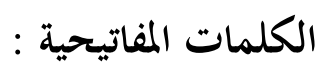

$$
\begin{aligned}
& \text { ا - الاتفاق النووي : ص 0 ، ص V ، ص م ، ص } 9 \text {. }
\end{aligned}
$$

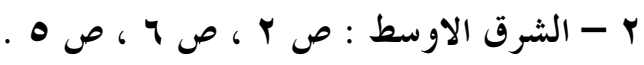

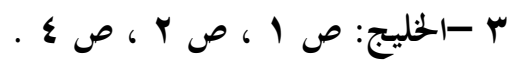

\section{Summary}

The fundamental turning point in American policy towards the Iran was the success of the Islamic revolution in Iran 1979. Since than U S policy has been hostile to Iran. After the events 11 September 2001 , there was an American idea of dialogue with some countries opposed to US policy, including Iran . In 2004 the United States launched the Greater Middle East project, which contain a range of political, economic and cultural proposals for the region, all of which were in the interest of the United States and ( Israel ), which Iran opposed. The failure of U S projects in region prompted the United States to agree with Iran on the nuclear file . On 8 May 2018 U S President Donald Trump officially announced that the United States was out of the nuclear agreement with Iran. Then on 5 November the United States imposed a package of sanctions on the 
Islamic Republic of Iran . But the U S withdrawal from the agreement and the imposition of sanctions has been rejected by most of the word, which means that the policy of U S containment will continue.

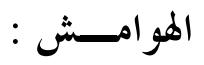

( 1 ) السيد زهرة ، " استرتيجية القوتين الاعظم وقضايا الامن في الحليج " ، مجلة الفكر الاستراتيجي العربي ، العدد ץ ،

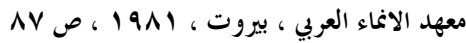

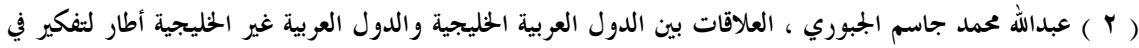

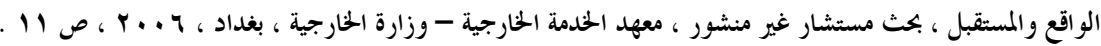
(r) ) ظافر محمد العجمي ، امن الخليج العربي : تطوره واشكالياته من منظور العلاقات الاقليمية والدولية ، مركز

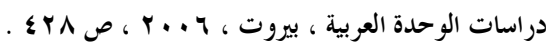

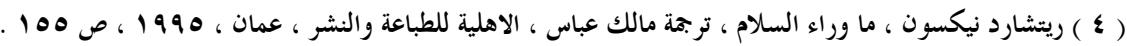

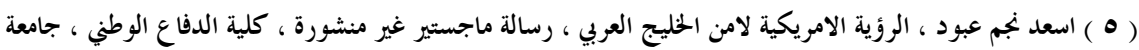

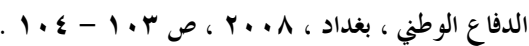

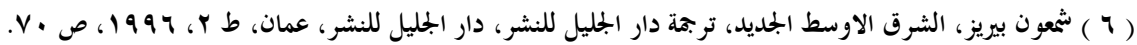

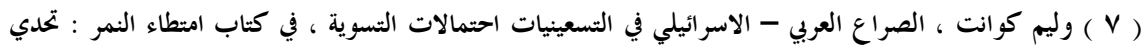

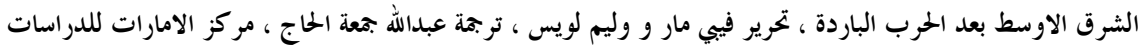

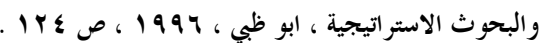

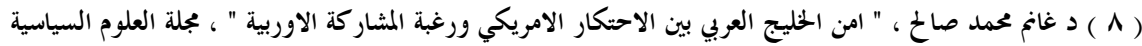

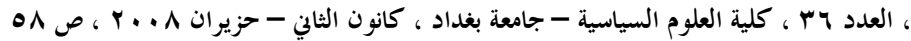

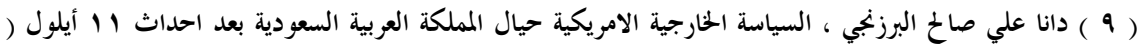

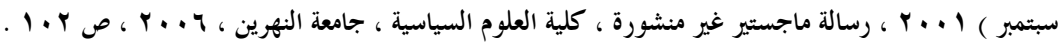

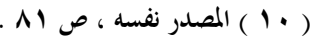

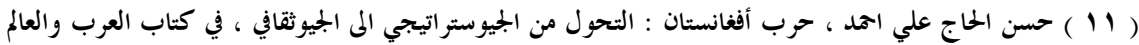

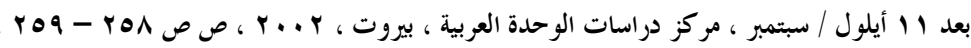

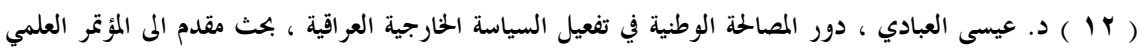

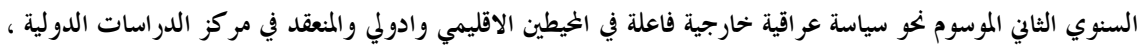

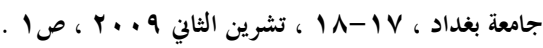

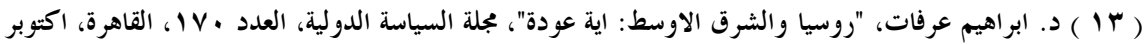

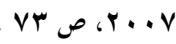
( 1 ( ) تدخل ايران في الحرب الاهلية السورية ، ويكيبيديا ، الموسوعة الحرة ‘https://ar.m.wikipedia.org . 2018 / 9 / 2 .

$$
\text { ( } 10 \text { ) الحروج الامريكي من الاتفاق النووي مع ايران ، ويكيبيديا ، الموسوعة الحرة }
$$

،https://ar.m.wikipedia.org . 2018 / 9 / 11. 